\title{
Adverse childhood experiences and trauma informed care: the future of health care
}

\author{
Resmiye Oral' ${ }^{1}$ Marizen Ramirez ${ }^{2}$, Carol Coohey ${ }^{3}$, Stephanie Nakada ${ }^{4}$, Amy Walz ${ }^{4}$, Angela Kuntz ${ }^{4}$, Jenna Benoit ${ }^{1}$ and \\ Corinne Peek-Asa ${ }^{2}$
}

Adverse childhood experiences (ACEs) are related to shortand long-term negative physical and mental health consequences among children and adults. Studies of the last three decades on ACEs and traumatic stress have emphasized their impact and the importance of preventing and addressing trauma across all service systems utilizing universal systemic approaches. Current developments on the implementation of trauma informed care (TIC) in a variety of service systems call for the surveillance of trauma, resiliency, functional capacity, and health impact of ACEs. Despite such efforts in adult medical care, early identification of childhood trauma in children still remains a significant public health need. This article reviews childhood adversity and traumatic toxic stress, presents epidemiologic data on the prevalence of ACEs and their physical and mental health impacts, and discusses intervention modalities for prevention.

\section{CHILDHOOD ADVERSITY: DEFINITION AND SCOPE}

Childhood adversity may potentially have detrimental effects on long-term health (1). Adversity may include discrete events or ongoing circumstances that are outside of the child's control and are perceived as negative by the child $(1,2)$. The cumulative burden of adverse experiences has been shown to cause negative effects on physiological, cognitive, behavioral, and psychological functions (2).

The Adverse Childhood Experiences (ACEs) study focused on most common types of adversity that are encountered in the United States. These 10 ACEs included child abuse (emotional, physical, or sexual), child neglect (emotional or physical), and household dysfunction (domestic violence, substance abuse, mental illness or criminal activity, or parental absence) $(3,4)$. Subsequently, extreme economic adversity, bullying, school violence, and community violence have been described to be other commonly encountered ACEs (5). Other forms of adversity described in the literature include traumatic loss of a loved one, sudden and frequent relocations, serious accidents, lifethreatening childhood illness/injury, pornography (exposure or participation), prostitution, natural disaster, kidnapping, torture, war, refugee camps, and terrorism (3-7). Other studies specifically focused on identifying ACEs in children in real time and reported that major childhood adversities, including growing up in poverty, peer rejection and lack of friends, poor school performance, property crime, and witnessing community violence, are associated with increased lifelong risk for negative life events and negative health outcomes as well. Measuring childhood adversities during childhood has been shown to offer improvements to the original ACE scale by examining more short-term behavioral and emotional symptoms that may serve as a link between ACEs and long-term health problems $(8,9)$.

\section{TRAUMATIC TOXIC STRESS: HOW ACES AFFECT NEUROLOGICAL FUNCTIONING}

Health care professionals are becoming continually more aware of the social and environmental determinants of health, and the multiple effects of the environment on health outcomes are becoming increasingly better defined.

\section{Physiologic/Positive Stress, Tolerable Stress, and Traumatic Toxic Stress}

Stressors encountered throughout life may be experienced in different ways $(1,2)$ : When a dog barks at a child, or when preparing for an examination, "fight or flight" reaction may help the child generate the inner resources to deal with the stressor, which helps survival and growth. Such stressors are positive/physiological stressors. When a child experiences an illness that requires multiple invasive interventions, this stressor may be perceived as tolerable stress in the presence of supporting environmental factors such as nurturing relationships. Chronic/sustained stressors in the absence of a supportive environment on the other hand may lead to toxic stress as follows:

Stress response involves engagement of two primary systems: the hypothalamic-pituitary-adrenal (HPA) axis and the sympathetic nervous system $(1,2,10,11)$. These systems work in collaboration to respond to both acute stressors and chronic/ sustained stressors. The activation of the HPA axis begins in the hypothalamus by the release of proinflammatory cytokines that trigger corticotrophin-releasing hormone, which stimulates the release of adrenocorticotropin-releasing hormone

\footnotetext{
'Department of Pediatrics, University of lowa, lowa City, lowa; ${ }^{2}$ College of Public Health, University of lowa, lowa City, lowa; ${ }^{3}$ School of Social Work, University of lowa, lowa City, lowa; ${ }^{4}$ Carver College of Medicine, University of lowa, lowa City, lowa. Correspondence: Resmiye Oral (resmiye-oral@uiowa.edu)

Received 17 April 2015; accepted 23 August 2015; advance online publication 4 November 2015. doi:10.1038/pr.2015.197
} 


\section{Review | oraletal.}

from the anterior pituitary. Adrenocorticotropin-releasing hormone leads to the release of cortisol, norepinephrine, and epinephrine from the adrenal cortex. These stress hormones stimulate a myriad of responses from various organ systems including hepatic (gluconeogenesis), cardiovascular (increasing heart rate and blood pressure), respiratory (dilating the bronchioles), and many others $(11,12)$. Once the HPA axis is activated and cortisol is released, a negative feedback loop works to mediate the response. This feedback loop acts as a moderator to keep the stress response from becoming harmful. In physiologic and tolerable stress response, this feedback loop, as well as the elimination of the environmental stressor, helps the spike in stress hormones return to baseline quickly and easily $(11,12)$.

In traumatic toxic stress (TTS) however, chronic negative environmental factors can lead to chronic or sustained stress response system activation. This chronic activation has the ability to lead to the disruption of the structure and function of the neuroendocrine and immune systems (10). Thus, excess cortisol level in the circulation is sustained with subsequent chronic activation of the HPA axis (3). In the short term, this overactivation can result in an overload of cortisol, and in the long term, a relative lack of cortisol (2).

Both of these deviations may lead to negative health consequences (10). Too much cortisol suppresses the immune response and increases the chance of infection, while too little cortisol leads to the inflammatory response persisting after it is no longer needed (3). Animal studies have linked poorly responsive HPA axis to a variety of autoimmune diseases including rheumatoid arthritis, systemic lupus erythematosus, Sjogren's syndrome, fibromyalgia, and chronic fatigue syndrome. In humans, TTS has been linked to prolonged wound healing, decreased antibody production after vaccination, and susceptibility to viral infection $(2,13)$.

\section{Neurologic Remodeling in the Context of TTS}

The dysregulation of the HPA axis can also lead to long-term modifications on multiple organ systems, most notably in the brain $(1,14)$. TTS has been shown to lead to changes, especially in the more susceptible young brain, which can lead to long-term effects on both physiology and behavior $(2,14,15)$. The genes that determine how the body responds to stress are highly subject to epigenetic modifications (16). Epigenetic changes may occur via DNA methylation and histone acetylation that modify gene expression. While some of these modifications are transient, others are programmed early in life and will remain embedded throughout the child's lifetime with the potential to be passed on to the next generation (16). It was also shown that the three regions of the brain that are most prominently affected by TTS are laden with glucocorticoid receptors. These regions are the hippocampus, the prefrontal cortex, and the amygdala $(10,11,13,14)$.

The hippocampus, intimately involved in the formation of new memories and learning, undergoes proliferation throughout childhood. When the brain is subjected to remodeling via TTS in animals, hippocampal neuronal proliferation is significantly suppressed, which leads to significant longterm impairments in learning and new memory formation $(11,14,15)$.

Children who are victims of chronic abuse may experience remodeling in the amygdala as well. The amygdala, part of the limbic system, is activated in response to stress and has been shown to generate impulsive behaviors $(11,15)$. In the context of TTS, dendritic growth and proliferation in the amygdala lead to an increase in impulsive behavior $(11,14)$. Conversely, TTS causes the prefrontal cortex, the part of the brain that is dedicated to planning and impulse control, to be underdeveloped and have fewer synaptic connections leading to poor impulse control $(14,15)$.

These regional brain alterations can ultimately convert an individual's physiologic stress responses into toxic stress responses, through which the person perceives benign experiences as life-threatening events (2). These alterations in brain architecture may also promote the development of social and behavioral coping "skills" that are maladaptive with subsequent health consequences $(1,2,17)$.

\section{EPIDEMIOLOGY OF CHILDHOOD ADVERSITY}

The original ACEs study on more than 17,000 adult participants showed $64 \%$ of the population surveyed reported at least one ACE (4). In 2010, five states, including Arkansas, Louisiana, New Mexico, Tennessee, and Washington, found similar results (18): Of 26,229 subjects that were surveyed, $59 \%$ reported having experienced at least one ACE. A 2012 survey of Iowans revealed that $55 \%$ of Iowa adult population had experienced at least one ACE (19).

Studies also showed that ACEs are likely to co-occur $(4,18-$ 20 ). The original ACEs study revealed that $13 \%$ of the respondents had four or more ACEs during childhood compared to $15 \%$ of the respondents in both the 2010 Centers for Disease Control and Prevention multistate study and the Iowa study $(4,18,19)$.

The International Society for the Prevention of Child Abuse and Neglect created child abuse screening tools for global use, which provide opportunity to screen for ACEs as well $(21,22)$. These tools were used in the multinational Balkan Epidemiology of Child Abuse and Neglect study, which revealed the presence of at least one ACE in $65-83 \%$ of the 42,272 children surveyed in nine Balkan countries (22).

\section{IMPACT OF CHILDHOOD ADVERSITY AND TTS ON HEALTH}

The original ACEs study by Felitti et al. in 1998 set out to test the cumulative and long-term effect of several types of ACEs, not just one type of childhood victimization, on adult wellbeing. This study, which has led to over 50 publications, has profoundly changed the focus of the child maltreatment field by shifting the focus from the effect of individual types of childhood victimization to the cumulative effect of ACEs on child and adult well-being (3,4,20,23-33).

Other researchers have also shown that ACEs predict higher rates of negative health outcome $(3,4,20,24-32,34-44)$. These outcomes can be loosely divided into (i) health risk behaviors 
(ii) leading causes of death and other chronic health problems, (iii) poor mental health, and (iv) other impacts $(4,18,42)$.

\section{Health Risk Behaviors}

The number of ACEs has been found to be related to several health-risk behaviors, including substance abuse (alcohol and illicit substances) $(4,18-20,28-30)$, tobacco use $(4,18,19,28,30)$, sexual behaviors that contribute to unintended pregnancy and sexually transmitted diseases $(28,32)$, and obesity $(4,18,20,33)$. Having experienced four or more ACEs increases the rate of smoking (2.2 times), alcoholism (7.4 times), substance abuse (4.2 times), intravenous illicit substance abuse (11.3 times), severe obesity (1.6 times), and sexual intercourse with 50 or more partners (3.2 times) with a clear dose-response relationship between the number of ACEs and the adoption of these highrisk behaviors $(4,18-20)$. These behaviors have been referred to as a "trauma organized" lifestyle and predispose individuals to mental and physical illness throughout life $(23,45)$. Thus, the neurological changes that are mediated by TTS, a "trauma organized lifestyle," and the circumstances that are associated with limited access to health care, together are believed to lead to increased risk of morbidity and mortality $(4,34,44)$.

\section{Leading Causes of Disease and Other Chronic Diseases}

Childhood trauma can also lead to several leading causes of death among adults, including heart disease and stroke $(25,28)$, liver disease (28), lung cancer (34), and chronic obstructive pulmonary disease $(26,28)$, the relationship becoming more apparent with four or more ACEs. An increasing number of ACEs has also been found to be related to autoimmune diseases, such as rheumatoid arthritis $(27,28)$, frequent headaches $(35,40)$, primary insomnia (36), and several metabolic risk biomarkers (obesity, high blood pressure, high total cholesterol, low high-density lipoprotein cholesterol, high glycated hemoglobin) (37). Some of these health outcomes have also been found to be associated with changes in immune function as a result of TTS $(2,3,13)$.

\section{Mental Health}

There is an extensive empirical literature on the relationship between the cumulative number of ACEs and mental health challenges. Researchers have found a relationship between the number of ACEs and learning and behavioral problems among children and adolescents (20,23,28-31), and somatic disorders $(39,40)$, hallucinations $(3,28)$, anxiety and obsessivecompulsive disorders $(30,41)$, depression, and suicide attempts (28-31) among adults. Specifically, four or more ACEs increased the risk of depression (4.5 times) and suicide attempts (12.2 to 15.3 times) $(4,19)$.

Individuals who have experienced multiple traumas and resultant emotional dysregulation may present with posttraumatic stress disorder characterized with dissociation and increased automatic reactivity (46-49). Patients with dissociative posttraumatic stress disorder also exhibit emotional under-engagement creating barriers in establishing and maintaining healthy and supportive relationships, which is the basis for recovery from stress. Thus, these individuals may have difficulties in responding to traditional treatment (47).

\section{Other Impacts}

Finally, researchers have found that people who reported more ACEs were more likely to report poor or fair health $(33,42)$, or a lower sense of well-being (43), have poorer access to medi$\mathrm{cal} /$ mental health services $(4,19,42)$, be less satisfied with their lives (30), have higher work-related problems/unemployment (4), and die prematurely by as much as 20 years earlier $(4,34,43)$ than people who reported fewer ACEs. Finally, an increasing number of ACEs was found to be related to an increase in health care utilization/costs $(28,42)$.

\section{APPROACHES TO REDUCING THE BURDEN OF ACES}

The high population prevalence of ACEs and their association with a wide variety of negative outcomes support the need to prioritize ACEs prevention. Given the complex interplay between the individual, the family, the community, and the larger sociopolitical structure, the socio-ecological model provides a good conceptual framework to guide prevention. To have the desired multilevel effect, strategies to prevent the occurrence of ACEs and their adverse impacts are needed at every level (50).

Following the general public health approach, primary prevention includes efforts to prevent ACEs so that children grow up with less exposure to adversity and are less likely to have children of their own who experience ACEs (Table 1) (51). Secondary prevention includes efforts immediately after an ACE to reduce the immediate and short-term consequences. Tertiary prevention includes efforts to treat and reduce longterm consequences of ACEs (51).

Understanding ACE prevalence and risk factors as well as identifying individuals who have experienced ACEs is a critical element in a comprehensive approach to prevention. However, a focus on primary prevention of ACEs, in which the incidence of ACEs is reduced at the population level, will have the greatest individual and societal impact $(52,53)$. In order to accomplish this, the interventions should focus on strengthening individual and community resilience rather than solely identifying and responding to individual ACEs by strengthening communities and reducing resource disparity. For example, child abuse prevention programs such as emergency nurseries, programs that provide referrals to services such as homeless shelters and food pantries, and increased availability of mental health and substance abuse treatment can reduce the risk for ACE events at the population level.

An increasing number of prevention and intervention approaches are becoming available at various levels: At the individual and family levels, primary prevention programs such as Circle of Security that improve parent-child attachment can reduce ACE experiences such as child abuse and neglect (54). Other programs, such as the Period of Purple Crying prevent specific types of abuse, such as shaken baby syndrome (55).

Targeted primary prevention programs at the community and societal levels are rare. Three of 17 studies evaluating 


\section{Review oraletal.}

Table 1. Primary, secondary, and tertiary response to adverse childhood events

\begin{tabular}{|c|c|c|}
\hline Phase & Goal & Examples \\
\hline Primary prevention & $\begin{array}{l}\text { Prevent the occurrence of adverse } \\
\text { childhood events so that fewer children } \\
\text { experience ACEs }\end{array}$ & $\begin{array}{l}\text { - Programs that prevent child abuse and neglect } \\
\text { - Programs that increase family and community stability and resilience } \\
\text { - Programs that teach positive and effective parenting skills }\end{array}$ \\
\hline Secondary prevention & $\begin{array}{l}\text { Reduce the severity and acute } \\
\text { consequences of the child adverse } \\
\text { experience, thereby reducing the } \\
\text { incidence of adverse outcomes } \\
\text { associated with ACEs }\end{array}$ & $\begin{array}{l}\text { - Programs that identify and intervene on families experiencing violence and abuse } \\
\text { - Trauma informed care to identify and immediately intervene on ACEs } \\
\text { - Psychological first aid that reduces psychological impact of trauma }\end{array}$ \\
\hline Tertiary prevention & $\begin{array}{l}\text { Treat and reduce the long-term } \\
\text { consequences of ACEs }\end{array}$ & $\begin{array}{l}\text { - Trauma informed care in health care and service agencies that integrate past } \\
\text { traumatic experiences into, for example, care for chronic illnesses } \\
\text { - Programs that identify and reduce risky health behaviors associated with ACEs } \\
\text { - Social marketing campaigns that build empathy with ACE consequences }\end{array}$ \\
\hline
\end{tabular}

These phases are cyclical and can influence each other. For example, an individual who has an ACE-related health outcome may be less likely to introduce ACEs into the life of their child if they have received trauma informed care to reduce the consequences of their health outcome.

ACE, adverse childhood experience.

universal campaigns measured child abuse as an outcome, and of these, two of the three studies found significant decreases (52). Triple-P or Positive Parenting Program is an example of a universal program that supports positive parenting at the individual, family, community, and societal levels through targeted education and social campaigns (1).

Secondary strategies have been primarily focused at the individual and family levels. Child protective service agencies are one example, which are widespread but vary markedly in different countries and states and often address the most severe cases of child maltreatment. New programs that attempt to identify and respond to adverse experiences earlier, and before they are severe enough to require hospital treatment or an official agency response, are growing in priority such as home visiting programs that are found to be effective in reducing child abuse and neglect and improving family function (56).

Interventions such as psychological first aid (PFA) implemented in nonfamily settings, such as schools or health facilities, may provide the opportunity to identify effected children early and to increase program reach. Although originally developed as a response to disasters, PFA provides a framework that has been applied to other personal adverse experiences such as interpersonal violence and family trauma (57). PFA identifies children and their caregivers immediately after a life stressor and provides information, education, comfort, and support, which results in acceleration of recovery, promotion of mental health, and increased resiliency $(58,59)$. Recently, the World Health Organization published "Psychological first aid: Guide for field workers," which describes crises ranging from "war to natural disasters, accidents, fires, and interpersonal violence." (60). Adults trained in PFA report increased knowledge, skills, and self-efficacy in applying skills to support youth with histories of trauma $(61,62)$. One study also reported PFA being effective in improving connectedness and stress among youth traumatized by a disaster, bullying, death or illness of a family member, or injury (59). Thus, PFA is an ideal program that may be delivered by all members of a trauma-informed organization, even by those without advanced mental health training.
In addition, parent-child interaction therapy (PCIT) and child parent psychotherapy (CPP) are also emerging evidencebased treatment modalities to prevent and manage ACEs and their impact on the intrafamilial relationships as early as possible via a two-generational approach $(63,64)$.

Cognitive behavioral therapy is the most common approach to reduce psychological symptoms from trauma that can be directed at all family members. Systematic reviews of the effectiveness of cognitive behavioral therapy on adults show that is has some effect on reducing symptoms of posttraumatic stress disorder, depression, and anxiety and has the potential to change dysfunctions of the nervous system $(65,66)$. New evidence suggests that family approaches are best (67). Evidence for cognitive behavioral therapy for children is mixed, and increasing knowledge about the pediatric brain may help inform child-based approaches (68).

Other tertiary approaches are found predominantly in educational, medical, child welfare, and justice settings. TIC, which is being integrated in settings such as health care, service agencies for high-risk families, and in correctional facilities, help service providers become aware of the effects of ACEs and how to integrate compassionate care. Although TIC is among the most prevalent strategies to address ACEs, few outcome evaluation studies have been conducted (51,69-71).

Critical gaps exist in the evidence base for responding to ACEs, especially for primary prevention at the community and sociopolitical levels. Gaps in our foundational knowledge about the global prevalence and cultural differences in response to ACEs also hinder prevention.

\section{TRAUMA INFORMED CARE}

TIC is considered a comprehensive multilevel approach that shifts the way organizations view and approach trauma. According to the Substance Abuse and Mental Health Services Administration (SAMHSA) (72),

"A program, organization, or system that is trauma-informed realizes the widespread impact of trauma and understands 
potential paths for recovery; recognizes the signs and symptoms of trauma in clients, families, staff, and others involved with the system; and responds by fully integrating knowledge about trauma into policies, procedures, and practices, and seeks to actively resist re- traumatization."

The impetus for TIC stems from a realization that systems of care that serve children are often unaware of trauma experiences of their clientele, which may lead to re-traumatization and failure to provide appropriate referrals $(73,74)$. TIC involves validation and recognition of the effects of traumatic events, common coping strategies, and effective treatments. Transforming organizations into trauma-informed systems entails organizational changes and the development of culturally sensitive infrastructure that is responsive to the needs of traumatized individuals (74).

The SAMHSA promotes the use of six broad principles for TIC (74):

1. Safety. Promoting a sense of safety involves a conscious effort to ensure that all members and clients of an organization are physically and emotionally safe.

2. Trustworthiness and transparency. Organizations must approach decisions with transparency and engender trust of staff and their clientele.

3. Peer support. Peers, which include family of traumatized children as well as individuals who have lived with histories of trauma, can be critical resources for support.

4. Collaboration and mutuality. All members of an organization can equally contribute to the healing of children impacted by adverse experiences.

5. Empowerment, voice, and choice. Developing plans of action for clients requires patient-centered approaches that empower clients.

6. Cultural, historical and gender issues. Efforts must be culturally sensitive and free of prejudices based on biases and stereotypes.

Efforts to integrate these principles require support at the top levels of an organization and the implementation of policies and protocols to assure that trauma-informed activities are carried out by staff (51). As an example, the architecture of patient rooms and the physical environment must be inviting and pose no risk for re-traumatization.

Another essential component of TIC identified by SAMHSA and other researchers is the implementation of screening, assessment, and trauma treatment services to identify children who have experienced adversity $(72,74)$. Adoption of traumascreening procedures should be coupled with screening for resiliency, family functional capacity, community-based resources, behavioral and neuropsychological assessments, and previous interventions for trauma (74).

Trauma-informed organizations must adopt trauma-specific interventions that work in concert with screening for trauma. Although SAMHSA provides a list of known trauma-specific interventions, most of which are based on psychosocial educational empowerment principals and require professional therapists for delivery, none are currently being endorsed as for use in concert with TIC (75). Others, however, are discussing the need for integrating specific evidence-based strategies such as parent-child interaction therapy and child parent psychotherapy into trauma-informed systems that service youth who may have histories of trauma $(64,72)$.

\section{Implementation of TIC}

A number of communities have embraced TIC to support children with adverse experiences. In 2000, Tarrant County in Texas formed a "mental health connection" collaboration of medical, county, city, and child health agencies and developed a strategic plan that involved the development of "learning communities" engaged in implementing local efforts in prevention, which included education and training; screening and referral through service agencies; and implementation of trauma-focused cognitive behavioral therapy sessions (33). The community State agencies are now beginning to adopt trauma-informed approaches, including the Oregon Health Authority and New York's juvenile justice system (72).

In 2005, the National Center for Trauma Informed Care was created by SAMHSA to provide training and technical assistance to support communities and organizations interested in becoming trauma-informed via in-person consultation and through virtual networks, and by providing materials, curricula, and resources (75). The Child Welfare Information Gateway is another agency providing support specifically to child welfare agencies to develop trauma-informed systems (76).

New research is emerging on the effectiveness of TIC in improving health care delivery. One study reported that primary care providers trained in TIC had increased patientcentered interactions and patient satisfaction (69). Suarez et al. (77) reported early results of improved outcomes among at-risk girls serviced by Project Kealeahou in Hawaii. Centers from California, Massachusetts, Ohio, Wisconsin, Iowa, among others, are also implementing TIC in medical setting with promising positive outcome results (64). Additional research is needed to fully understand the impacts of trauma informed approaches on children.

\section{STATEMENT OF FINANCIAL SUPPORT \\ None.}

Disclosure: The authors report no conflict of interest.

\section{REFERENCES}

1. Garner AS, Shonkoff JP; Committee on Psychosocial Aspects of Child and Family Health; Committee on Early Childhood, Adoption, and Dependent Care; Section on Developmental and Behavioral Pediatrics. Early childhood adversity, toxic stress, and the role of the pediatrician: translating developmental science into lifelong health. Pediatrics 2012;129:e224-31.

2. Shonkoff JP, Garner AS, Siegel BS, et al. The lifelong effects of early childhood adversity and toxic stress. Pediatrics 2012;129:232-46.

3. Dube SR, Anda RF, Felitti VJ, Chapman DP, Williamson DF, Giles WH. Childhood abuse, household dysfunction, and the risk of attempted suicide throughout the life span: findings from the Adverse Childhood Experiences Study. JAMA 2001;286:3089-96.

4. Felitti VJ, Anda RF, Nordenberg D, et al. Relationship of childhood abuse and household dysfunction to many of the leading causes of death in 
adults. The Adverse Childhood Experiences (ACE) Study. Am J Prev Med 1998;14:245-58.

5. National Child Traumatic Stress Network. Types of traumatic stress, 2015. (http://www.nctsn.org/trauma-types.)

6. Center for the Study of Traumatic Stress. The impact of kidnapping, shooting and torture on children, 2015. (http://www.cstsonline.org/ assets/media/documents/CSTS_impact_kidnapping_shooting_torture_ children.pdf.)

7. Kessler RC, McLaughlin KA, Green JG, et al. Childhood adversities and adult psychopathology in the WHO World Mental Health Surveys. Br J Psychiatry 2010;197:378-85.

8. Finkelhor D, Shattuck A, Turner H, Hamby S. Improving the adverse childhood experiences study scale. JAMA Pediatr 2013;167:70-5.

9. Marie-Mitchell A, O'Connor TG. Adverse childhood experiences: translating knowledge into identification of children at risk for poor outcomes. Acad Pediatr 2013;13:14-9.

10. Johnson SB, Riley AW, Granger DA, Riis J. The science of early life toxic stress for pediatric practice and advocacy. Pediatrics 2013;131:319-27.

11. Elenkov IJ, Chrousos GP. Stress system-organization, physiology and immunoregulation. Neuroimmunomodulation 2006;13:257-67.

12. Carroll TB, Aron DC, Findling JW, Tyrrell B. Glucocorticoids and adrenal androgens. In: Gardner DG, Shoback D, eds. Greenspan's Basic and Clinical Endocrinology, 9th edn. New York: McGraw-Hill, 2011:285-327.

13. Webster JI, Tonelli L, Sternberg EM. Neuroendocrine regulation of immunity. Annu Rev Immunol 2002;20:125-63.

14. National Scientific Council on the Developing Child. Excessive stress disrupts the architecture of the developing brain: Working Paper 3. Updated Edition, 2015. (http://developingchild.harvard.edu/resources/reports_ and_working_papers/working_papers/wp3/.)

15. Brodal P. The Central Nervous System: Structure and Function, 3rd edn. New York: Oxford University Press, 2004.

16. National Scientific Council on the Developing Child. Early experiences can alter gene expression and affect long-term development: Working Paper No. 10, 2015. (http://developingchild.harvard.edu/index.php/resources/ reports_and_working_papers/working_papers/wp10/.)

17. Shonkoff JP, Boyce WT, McEwen BS. Neuroscience, molecular biology, and the childhood roots of health disparities: building a new framework for health promotion and disease prevention. JAMA 2009;301:2252-9.

18. Centers for Disease Control and Prevention. Adverse childhood experiences reported by adults --- five states, 2009. MMWR Morb Mortal Wkly Rep 2010;59:1609-13.

19. Iowa Aces 360. Adverse childhood experiences in Iowa: a new way of understanding lifelong health, 2015. (http://www.iowafoodandfitness.org/ uploads/PDF_File_74101481.pdf.)

20. Burke NJ, Hellman JL, Scott BG, Weems CF, Carrion VG. The impact of adverse childhood experiences on an urban pediatric population. Child Abuse Negl 2011;35:408-13.

21. Zolotor AJ, Runyan DK, Dunne MP, et al. ISPCAN Child Abuse Screening Tool Children's Version (ICAST-C): instrument development and multinational pilot testing. Child Abuse Negl 2009;33:833-41.

22. CORDIS: Community Research and Development Information Service. Final Report Summary - BECAN (Balkan Epidemiological Study on Child Abuse and Neglect), 2015. (http://www.cordis.europa.eu/result/ rcn/58856_en.html.)

23. Finkelhor D, Ormrod RK, Turner HA. Poly-victimization: a neglected component in child victimization. Child Abuse Negl 2007;31:7-26.

24. Anda RF, Croft JB, Felitti VJ, et al. Adverse childhood experiences and smoking during adolescence and adulthood. JAMA 1999;282:1652-8.

25. Dong M, Giles WH, Felitti VJ, et al. Insights into causal pathways for ischemic heart disease: adverse childhood experiences study. Circulation 2004;110:1761-6.

26. Anda RF, Brown DW, Dube SR, Bremner JD, Felitti VJ, Giles WH. Adverse childhood experiences and chronic obstructive pulmonary disease in adults. Am J Prev Med 2008;34:396-403.

27. Dube SR, Fairweather D, Pearson WS, Felitti VJ, Anda RF, Croft JB. Cumulative childhood stress and autoimmune diseases in adults. Psychosom Med 2009;71:243-50.
28. Felitti VJ, Anda RF. The relationship of adverse childhood experiences to adult medical disease, psychiatric disorders, and sexual behavior: implications for healthcare. In: Lanius R, Vermetten E, eds. The Hidden Epidemic: The Impact of Early Life Trauma on Health and Disease. Cambridge University Press, 2010:77-87.

29. Pilowsky DJ, Keyes KM, Hasin DS. Adverse childhood events and lifetime alcohol dependence. Am J Public Health 2009;99:258-63.

30. Mersky JP, Topitzes J, Reynolds AJ. Impacts of adverse childhood experiences on health, mental health, and substance use in early adulthood: a cohort study of an urban, minority sample in the U.S. Child Abuse Negl 2013;37:917-25.

31. Schilling EA, Aseltine RH Jr, Gore S. Adverse childhood experiences and mental health in young adults: a longitudinal survey. BMC Public Health 2007;7:30.

32. Hillis SD, Anda RF, Felitti VJ, Nordenberg D, Marchbanks PA. Adverse childhood experiences and sexually transmitted diseases in men and women: a retrospective study. Pediatrics 2000;106:E11.

33. Dube SR, Cook ML, Edwards VJ. Health-related outcomes of adverse childhood experiences in Texas, 2002. Prev Chronic Dis 2010;7:1-9.

34. Brown DW, Anda RF, Tiemeier H, et al. Adverse childhood experiences and the risk of premature mortality. Am J Prev Med 2009;37:389-96.

35. Anda R, Tietjen G, Schulman E, Felitti V, Croft J. Adverse childhood experiences and frequent headaches in adults. Headache 2010;50:1473-81.

36. Bader K, Schäfer V, Schenkel M, Nissen L, Schwander J. Adverse childhood experiences associated with sleep in primary insomnia. J Sleep Res 2007;16:285-96.

37. Danese A, Moffitt TE, Harrington $\mathrm{H}$, et al. Adverse childhood experiences and adult risk factors for age-related disease: depression, inflammation, and clustering of metabolic risk markers. Arch Pediatr Adolesc Med 2009;163:1135-43.

38. Duke NN, Pettingell SL, McMorris BJ, Borowsky IW. Adolescent violence perpetration: associations with multiple types of adverse childhood experiences. Pediatrics 2010;125:e778-86.

39. Flaherty EG, Thompson R, Litrownik AJ, et al. Adverse childhood exposures and reported child health at age 12. Acad Pediatr 2009;9:150-6.

40. Maaranen P, Tanskanen A, Haatainen K, Koivumaa-Honkanen H, Hintikka J, Viinamäki H. Somatoform dissociation and adverse childhood experiences in the general population. J Nerv Ment Dis 2004;192:337-42.

41. Briggs ES, Price IR. The relationship between adverse childhood experience and obsessive-compulsive symptoms and beliefs: the role of anxiety, depression, and experiential avoidance. J Anxiety Disord 2009;23:1037-46.

42. Chartier MJ, Walker JR, Naimark B. Separate and cumulative effects of adverse childhood experiences in predicting adult health and health care utilization. Child Abuse Negl 2010;34:454-64.

43. Mc Elroy S, Hevey D. Relationship between adverse early experiences, stressors, psychosocial resources and wellbeing. Child Abuse Negl 2014;38:65-75.

44. Anda RF, Dong M, Brown DW, et al. The relationship of adverse childhood experiences to a history of premature death of family members. BMC Public Health 2009;9:106.

45. Bentovim A, Davenport M. Resolving the trauma organized system of sexual abuse by confronting the abuser. J Fam Therapy 1992;14:29-50.

46. Burns EE, Jackson JL, Harding HG. Child maltreatment, emotion regulation, and posttraumatic stress: the impact of emotional abuse. J Aggress Maltreatment Trauma 2010;19:801.

47. Powers A, Cross D, Fani N, Bradley B. PTSD, emotional dysregulation, and dissociative symptoms in a highly traumatized sample. J Psychiatr Res 2015:61;144-179.

48. American Psychiatric Association. Diagnostic and Statistical Manual of Mental Disorders: DSM-5. Washington, D.C: American Psychiatric Association, 2013.

49. Klimova A, Bryant RA, Williams LM, Felmingham KL. Dysregulation in cortical reactivity to emotional faces in PTSD patients with high dissociation symptoms. Eur J Psychotraumatol 2013;4.

50. Dahlberg LL, Krug EG. Violence-a global public health problem. In: Krug E, Dahlberg LL, Mercy JA, Zwi AB, Lozano R, eds. World Report on Violence and Health. Geneva, Switzerland: World Health Organization, 2002:1-56. 
51. DeCandia C, Guarino K, Clervil R. Trauma-informed care and traumaspecific services: a comprehensive approach to trauma intervention, 2015. (http://www.air.org/sites/default/files/downloads/report/TraumaInformed\%20Care\%20White\%20Paper_October\%202014.pdf.)

52. Poole MK, Seal DW, Taylor CA. A systematic review of universal campaigns targeting child physical abuse prevention. Health Educ Res 2014;29:388-432.

53. Prinz RJ, Sanders MR, Shapiro CJ, Whitaker DJ, Lutzker JR. Populationbased prevention of child maltreatment: the U.S. Triple $\mathrm{p}$ system population trial. Prev Sci 2009;10:1-12.

54. Cassidy J, Woodhouse SS, Sherman LJ, Stupica B, Lejuez CW. Enhancing infant attachment security: an examination of treatment efficacy and differential susceptibility. Dev Psychopathol 2011;23:131-48.

55. Barr RG, Rivara FP, Barr M, et al. Effectiveness of educational materials designed to change knowledge and behaviors regarding crying and shaken-baby syndrome in mothers of newborns: a randomized, controlled trial. Pediatrics 2009;123:972-80.

56. Garner AS. Home visiting and the biology of toxic stress: opportunities to address early childhood adversity. Pediatrics 2013;132:Suppl 2: S65-73.

57. National Research Council. Preparing for the Psychological Consequences of Terrorism: A Public Health Strategy. Washington, DC: The National Academies Press, 2003:99-135.

58. Berger R, Pat-Horenczyk R, Gelkopf M. School-based intervention for prevention and treatment of elementary-students' terror-related distress in Israel: a quasi-randomized controlled trial. J Trauma Stress 2007;20: 541-51.

59. Ramirez M, Harland K, Frederick M, Shepherd R, Wong M, Cavanaugh JE. Listen protect connect for traumatized schoolchildren: a pilot study of psychological first aid. BMC Psychol 2013;1:26.

60. World Health Organization, War Trauma Foundation and World Vision International. Psychological First Aid: Guide for Field Workers. Geneva, Switzerland: World Health Organization, 2011. (http://whqlibdoc.who.int/ publications/2011/9789241548205_eng.pdf?ua=1.)

61. Kelly CM, Mithen JM, Fischer JA, et al. Youth mental health first aid: a description of the program and an initial evaluation. Int J Ment Health Syst 2011;5:4.

62. Jorm AF, Kitchener BA, Sawyer MG, Scales H, Cvetkovski S. Mental health first aid training for high school teachers: a cluster randomized trial. BMC Psychiatry 2010;10:51.

63. The National Child Traumatic Stress Network. Treatments for Children and Families, 2015. (http://www.nctsn.org/content/treatments-childrenand-families.)
64. American Academy of Pediatrics (AAP). Conference on Violence, Abuse and Toxic Stress, San Francisco, CA, 30 July 2015-2 August 2015.

65. Forneris CA, Gartlehner G, Brownley KA, et al. Interventions to prevent post-traumatic stress disorder: a systematic review. Am J Prev Med 2013;44:635-50.

66. Porto PR, Oliveira L, Mari J, Volchan E, Figueira I, Ventura P. Does cognitive behavioral therapy change the brain? A systematic review of neuroimaging in anxiety disorders. J Neuropsychiatry Clin Neurosci 2009;21: 114-25.

67. Cohen JA, Mannarino AP. Trauma-focused cognitive behavior therapy for traumatized children and families. Child Adolesc Psychiatr Clin N Am 2015;24:557-70.

68. Jenkinson E, Williamson H, Byron-Daniel J, Moss TP. Systematic review: psychosocial interventions for children and young people with visible differences resulting from appearance altering conditions, injury, or treatment effects. J Pediatr Psychol; e-pub ahead of print 25 May 2015.

69. Green BL, Saunders PA, Power E, et al. Trauma-informed medical care: CME communication training for primary care providers. Fam Med 2015;47:7-14.

70. Hanson RF, Lang J. Special focus section: a critical look at trauma informed care (TIC) among agencies and systems serving maltreated youth and their families. Child Maltreat 2014;19:275.

71. Anda RF, Butchart A, Felitti VJ, Brown DW. Building a framework for global surveillance of the public health implications of adverse childhood experiences. Am J Prev Med 2010;39:93-8.

72. Substance Abuse and Mental Health Services Administration. SAMHSA's Concept of Trauma and Guidance for a Trauma-Informed Approach, 2015. (http://store.samhsa.gov/shin/content/SMA14-4884/SMA14-4884.pdf.)

73. Ko SJ, Kassam-Adams N, Wilson C, et al. Creating trauma-informed systems: child welfare, education, first responders, health care, juvenile justices. Prof Psychol-Res Pr 2008;39:396-404.

74. Harris M, Fallot RD. Envisioning a Trauma-Informed Service System: A Vital Paradigm Shift: New Directions for Mental Health Services. San Francisco, CA: Jossey-Bass, 2001:3-22.

75. Substance Abuse and Mental Health Services Administration. TraumaInformed Approach and Trauma-Specific Interventions, 2015. (http:// www.samhsa.gov/nctic/trauma-interventions.)

76. Childwelfare Information Gateway. Trauma-informed practice, 2015. (https://www.childwelfare.gov/topics/responding/trauma/.)

77. Suarez E, Jackson DS, Slavin LA, Michels MS, McGeehan KM. Project Kealahou: improving Hawai'i's system of care for at-risk girls and young women through gender-responsive, trauma-informed care. Hawaii J Med Public Health 2014;73:387-92. 